\title{
Liminal space or in limbo? Post Graduate Researchers and their personal pie charts of identity
}

\author{
Martin Compton, Danielle Tran
}

University of Greenwich

\section{Introduction}

It may seem self-evident that new PhD "students" in the United Kingdom conduct their research in a liminal space beyond taught undergraduate and postgraduate degrees but while they are not yet in the role of a full academic (whether or not that features as part of their career aspiration) the following questions can be raised: Are they still students? Are they researchers? Are they university staff or 'almost' staff? Do they teach? Should they teach? For many, it's an opaque boundary and one that we were interested in exploring from the perspectives of those negotiating it. Green (2007, p.153) goes so far as to say that, "doctoral education is as much about identity formation as it is about knowledge production". Whilst the achievement of 'Doctor' as the 'identity prize' clearly stimulates the PhD students' motivation, our experience of working closely with and talking to postgraduate researchers (PGRs) suggests that knowledge production remains, for most, the fundamental driver. Nevertheless, 'identity' as a lens through which we can perceive PGRs and their progress, and as a reflective lens through which they see their own evolution in academia has a value that we may not fully appreciate. Identity formation includes how PGRs formulate their own understandings of the ultimate 'object' of the $\mathrm{PhD}$ (Cotterall, 2015), what research actually means and entails (McCormack, 2004) and the positive and negative day to day experiences (Emmioğlu et al., 2017). In the worst instances, competing expectations collide and exploitation can be a consequence. We are fortunate that we have encountered nothing at all like this example cited in the Times Higher (2017):

It is well known that PhD students are widely seen by academics as a cheap workforce. But to be treated with such little respect by the people who are supposed to foster your career and help you to succeed is just not right in any workplace (anonymous contributor, unnamed university).

That such experiences can occur suggests that ongoing consideration of roles, expectations and perceptions of both PGRs and their supervisors is fundamental. It is likely that, by interacting with and supporting PhD students, we may both positively influence and better understand their perceptions of themselves; in consequence, we may well be able to enhance the support we give them.

Internationally there appears to be a tendency towards $\mathrm{PhD}$ students being seen (or even employed) as staff and there is a suggestion that some UK institutions are considering this model (Else, 2017). In that context, it is prudent to consider our own institutional perspectives and where we locate the PhD students. At this stage of our research, we are not seeking to distinguish experiences by discipline and we have focused on those at the earlier stages of their research. Although aware of possible limitations to our study, we sought to capture and focus on the PGRs' perceptions of themselves, as both the starting 
point for deeper discussions and a continuation of an existing study on identity and belonging amongst PGRs.

\section{PGR Roles and identity}

Whether they have an academic career in mind as a long term goal or not, the PGR is often seen as embarking on a research apprenticeship where "the established 'master' inducts the new apprentice into the 'mysteries' of the craft" (Yeatman, 1995, p. 9). Whether they are focused on an academic career, determinedly eschew that aspiration or are ambivalent, we realise that there is often discord amongst PGRs in relation to what they perceive to be the goals of their PhDs and how they are meant to get there. Our research seeks to examine how the PhD candidates we work with see themselves in the context of their physical, social and emotional environments. We are particularly interested in how they perceive the liminal space they are entering that bridges taught study and research. As Jazvac-Martek (2009) notes, 'Rarely considered are student intentions, motivations, or the variability of experiences and interactions that influence shifting identities' (p. 254).

There is a duality of identity or even a triality when it comes to PGRs, since they exist in a space that is simultaneously researcher, student, and often 'teacher' in the broad sense of supporting other students in their learning. In our own institution, informal discussions with key stakeholders suggest that there is a variance across departments and faculties that leads to significant differences in experience which in turn lead to often marked variance in self-concept, autonomy and comfort. The ramifications of this in terms of a PGR experience, how they perceive the University, their sense of belonging and how valued they feel are the primary goals of this ongoing research. A core component of one's sense of belonging is identity in a work/ study environment. How that identity is shaped by factors such as selfconcept, significant others, policy context and the pervading institutional and social cultures is of particular interest in this article. This research has primarily focused on the first year of study where PGRs begin research, start working with undergraduates and follow a series of mandatory taught courses as the first stages in a longer research programme. We have been investigating how they see themselves (in the context of their roles, position and day to day working) in the University and in particular, we focus on where they work, who they work with, their expectations and how much they feel 'part' of the University.

\section{Our focus}

Whilst there is a considerable body of research relating to professional identity in academics and the importance of a sense of belonging amongst students at school or undergraduate level (Hoffman et al., 2016), there is much less in respect of PGRs. There are of course some interesting studies pertaining to doctoral candidate role identity (see for examples Jazvac-Martek, 2009; Colbeck, 2008). A UK sector discussion about and acknowledgement of the variance in nomenclature, roles, responsibilities and regard afforded mean that we hope our case (an urban post-1992 institution with a considerable international PhD contingent) will present a useful contribution.

This case study spotlights just one small element of the wider research and looks at an output designed originally to stimulate thinking rather than generate data. However, we found that although, as planned, our initial activity provided a clarification of terms and common framework for the focus group discussions, it also offered some fascinating insights 
and acted as a source of data in its own right. Whilst we acknowledge the depth and complexity of identity theory, which could no doubt add insight to our analysis, we have been keen to capture and consider the rawness of these impressions as a cornerstone to an ongoing study. Our intent in examining their perceptions about identity and belonging and an associated rationalisation of these is to help with the ongoing strategies and mechanisms of support for PGRs. We hope this paper will provoke discussion about who we want PGRs to be and how the institution and supervisors interact with them.

\section{PGR Teaching, Learning and Assessment course (TLA)}

The participants involved were all registered PGR students on the Postgraduate Teaching, Learning, and Assessment (PGR TLA) course at the University of Greenwich. The aim of the six week course, which runs twice a year (once in the autumn term and once in the spring term and simultaneously in each case at two campuses: Medway and Greenwich Maritime), is to introduce PGRs to a range of teaching and learning approaches and essential concepts and strategies when beginning teaching in Higher Education (HE). A mixture of theory, preclass online activities, group discussions, practical assessments, and a written reflection combine to form a blended course for the PGRs. The course is compulsory and must be completed as part of the PGR development programme at Greenwich. This means that all PGRs, unless formally exempted, must register on the course, attend all classes and engage with all assessments. Until starting the course the PGRs are not supposed to do any demonstration, lab support or tutorial work. That it exists and is compulsory suggests the teaching function of PGRs is a valued and central component of the wider PGR programme. Medway is a STEM dominated campus and the research interests of the PGRs who were part of this cohort reflected this. There was a wider mix of research specialisms with the Greenwich Maritime cohort, ranging from Architecture to Music. However, for this particular case study, we are not distinguishing the disciplinary background of the PGRs and how or whether these have affected their pie chart responses. There is, of course, scope for future analysis based on this and other variables.

There are varying types of training and professional development opportunities that are made available to PGRs (both mandatory and optional) across HE institutions. These vary from one day introductions to more formal courses like our own. Some are connected directly to the Higher Education Academy (HEA) Associate Fellowship level of the United Kingdom Professional Standards Framework (UKPSF). Like many similar initiatives the PGR programme design is strongly connected to the national Researcher Development Framework (Vitae, 2017). Within that, the PGR TLA course encompasses the values that underpin the professional framework of Vitae that is evident in their four domains (2010). The design of the TLA programme also helps to support PGRs on the path to applying for Associate Fellowship of the HEA. Although it does not currently confer automatic recognition, the final session of the programme is focused on discussing the three dimensions of Areas of Activity, Core Knowledge, and Professional Values (HEA, 2017).

In the autumn term 2016-17, 16 PGRs were registered as part of the Greenwich cohort, and 18 registered as part of the Medway cohort. In the spring term 2016-17 there were 16 PGRs at Greenwich and 17 at Medway. 


\section{Methods and rationale}

For our wider and ongoing research we are using a multi strategy design utilising online questionnaires and focus groups. In the 2016-17 academic year we conducted four separate focus groups, one for each cohort. The first two were facilitated by one of the authors, the second two by a colleague as both the authors had taught sessions to those two cohorts. The focus groups were carried out at the end of the course, immediately after the final faceto-face session. For the focus groups, we devised an activity to engage the participants and orientate their thinking towards notions of identity and belonging. We called this activity the personal pie charts of identity. As stated, we wanted to use this as a prompt and as a 'warmer' activity but the ways in which the PGRs varied in their interpretation, the simplicity of the expression and the framing it afforded us suggested that we should look more closely at these pie charts. Central to the design of this task was what Guantlett and Holzwarth (2006) describe as a 'a happy side effect' of visual methods they have used to explore identities: 'Primarily the creative activity is the starting point for developing thoughts about personal experience and identity, which are ultimately communicated to the researcher.' (p.82). In fact, for us, the 'happy side effect' was how interesting the visual aspect was in itself. This report focusses primarily on what we have seen in those pie charts.

The pie chart creation as a data source can be represented as a 'participant- generated visual methodology' (Guillemin and Drew, 2010). Much of the literature focusses on how this methodology enables the articulation of difficult to express feelings and ideas. Whilst this is a less sensitive area to, say, mental illness or the consequences of chronic illness, we feel that the opportunity it afforded benefitted the participants, particularly those that are international PGRs and are still evolving confidence when it comes to expressing themselves in English. This is especially true of the science focused PGRs, many of whom hail from a range of non native English speaking backgrounds. We share the perspective offered by Guillemin and Drew (2010):

By fostering participation, these methodologies can be empowering... We suggest that visual methodologies offer a different approach that takes seriously participants as knowers. In addition, visual methodologies provide participants with the opportunity to produce an image that allows them to portray what is often difficult to express in words (p. 178).

Sheets of paper with an empty circle and basic guidance were handed to each student. On them was the request that they think about how they see themselves and what proportion of the self-conception pie they would give to themselves as 'student' and what to 'researcher', 'teacher'/ 'lecturer' or 'staff member'. Verbally, we suggested that they could use as many as they wished and use other terms if preferable. The terms we used are those most common in our own institutional documentation. We wanted to give each PGR the opportunity to reflect on their own roles in the University and decide for themselves how they see themselves within the institution but within a common frame of reference that could be used for comparative purposes and could also be layered upon and unpicked subsequently. We emphasised the impressionistic approach though a few from the science faculty were still clearly fazed by our unscrupulous disregard for precision: 


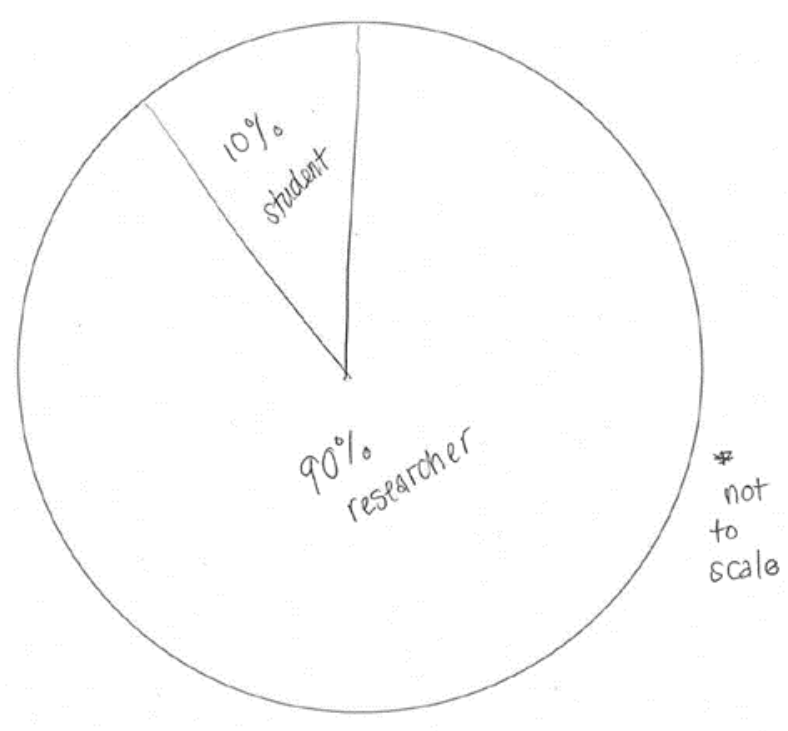

Figure 1: Sample pie chart with caveat (A12)

They were given around five minutes to complete the task. It can be seen on some of the finished pie charts that some divisions were re-worked, pointing to the careful decision making which the students were undergoing as they completed the pie chart. What drew our attention to the potential richness of such an activity for the intended purposes but also as a data source was the time, consideration and care many of them put into it. It was clear that although the five minute time allocation pushed the PGRs to make a slightly instinctive and immediate judgement in terms of how they perceive themselves, they nevertheless wanted to 'get it right' and some pondered for some considerable time and at least two of the total who completed the activity $(n=38)$ asked for a fresh sheet so they could make it clear. Some wrote percentages in and others used lines from which we can only approximate percentages. The pie charts presented below have been selected as representative and are numbered with a letter prefix ( $A$ =autumn; $S=$ spring) for convenience of cross referencing.

\section{Findings and discussion}

\section{Overview}

38 students took part in the pie chart activity. We found that the pie charts could be grouped into four categories:

1. The largest proportion placed a heavy emphasis on the researcher aspect of their identities (18 out of 38)

2. The next most frequent commonality were those that made an effort to split their pie chart into thirds (from the equal three way split to a range of varying proportions usually with research as the largest section) (11 out of 38)

3. A small but not insignificant minority of charts placed a heavy emphasis on perceiving themselves as being mainly a student (5 out of 38)

4. And a small number revealed an almost equal split between student and researcher (4 out of 38 ). 
Unsurprisingly, none had more than $40 \%$ for 'teaching'. This may be different of course in other institutions where the teaching role of $\mathrm{PhD}$ students is more integral to the role. Internationally the picture is different still, with $\mathrm{PhD}$ students often tasked with relatively large teaching or support functions, often with concomitant 'academic' status (Else, 2017). Although PGRs at the University are able to take up teaching positions as soon as they are registered on the PGR TLA, there may not be many opportunities available to them. Moreover, PGRs may be less concerned with taking up such responsibilities as they wish to focus more on the development of their research.

So what do these tendencies suggest? Category 1 reveals that most of the PGRs who participated in the task view themselves predominantly as the institutional nomenclature defines them, perceiving themselves as being 'more than a student'. 'Researcher' connotes exploration, discovery, new thresholds of knowledge and as latter discussions revealed suggests heightened importance and value. In discussions with the PGRs many made clear they felt it sounded more prestigious than 'student'. Whilst we provided no fixed definition of research, subsequent discussion relating to such factors as relationship with supervisors, collaboration, autonomy and even loneliness suggest that, like McCormack's (2004) longitudinal study of three PGRs, divergent expectations and experiences were prevalent.

In some ways, category 2 is unsurprising in that if you offer people three components they may be tempted to represent each of them. Few actually suggested categories other than those we suggested so a follow up exercise where these are participant defined would be interesting. On at least two occasions during the activity, PGRs commented that they would like to be doing more 'regular' student facing work. Others commented that they could not of course be 'teaching' in any sense of the word because that had yet to complete the mandatory PGR TLA which prompted a barrage of "well, in fact, I have been..." type rejoinders. Clarification of requirements for both supervisors and PGRs is therefore essential.

Since PGRs are not referred to as students in our university literature, even this figure in category 3 might be a surprise. They are commonly called PGR or PhD students in everyday parlance amongst academics however. It may suggest that some of the PGRs do not view their role as a PGR as one that is any more active or innovative than the role they had at university a few years before (a case perhaps of more of the same at a higher level). By labelling themselves as being more of a 'student' than anything else, these PGRs may be feeling as though their research is very much being guided by their supervisors on the classic 'master/ apprentice' model and, despite efforts here and elsewhere to encourage autonomy and independence earlier, at levels 6 and 7 in particular (QAA, 2010), either see themselves as dependent or have a more generalised view of what it means to be a 'students'. These students tend, of course, to still be in the very early stages of the PhD research, and therefore will likely be more reliant on the help of their supervisors. The degree to which this relationship is supportive or directive is likely to have a significant impact on the ongoing sense of autonomy and agency in terms of their research.

Another possible reason behind such labelling is the way in which the PGRs approach their $\mathrm{PhD}$. If $\mathrm{PGRs}$ choose to complete a $\mathrm{PhD}$ as an extension of a previous degree, their thesis may be viewed as a longer and more extensive dissertation, which is being supervised and guided by an expert academic. If such is the case, then the PGRs may approach their 
research in much the same way they would have approached a dissertation in the past making core efforts to evaluate existing knowledge but relying on the guidance of their supervisor to steer them in the right direction. For the latter, the PGRs may view their supervisor in much higher esteem and thus perceive a hierarchy between themselves and their supervisor, leading to a self labelling of 'student'. Crossouard and Pryor (2008) acknowledge the tendency in supervisors to adopt a hierarchical approach but propose that by 'invoking different identity positions' (pp.224-225) in themselves they can help support the evolution of the PGRs' academic identity.

Category 4 revealed an almost equal split between student and researcher. Colbeck (2008) suggests that 'When two identities with contrasting meanings and expectations are activated at the same time, an individual is likely to experience stress' (p.10) and, given the many systems, responsibilities and working protocols PGRs are faced with in the early stages of $\mathrm{PhD}$ study, we may do well to acknowledge this tension as a loci of stress and take steps to alleviate it. The split may point to tensions surrounding the PGRs' feelings towards their study, their supervisors, and their position as a PGR in the university. For Jazvac-Martek's (2009) longitudinal study, 'Findings highlight doctoral students taking on a large variety of both doctoral student and academic role identities during their doctoral studies and oscillating between these roles frequently over time' (p. 258). For PGRs who are in the early stages of their research and not taking on teaching duties, the role they have in terms of their study and place in the university may not feel much different to the ones they had when they were an undergraduate. For students experiencing the latter, they may associate themselves more with being a 'student' more in line with category three above. What we need to be alert to therefore is that these pie charts are a snapshot, a mere moment in time, and a significant experience could easily skew these self-concepts on a different day.

\section{An Evaluation of Selected Pie Charts}

In the section that follows, we have selected a sample of representative pie charts from each category for closer consideration.

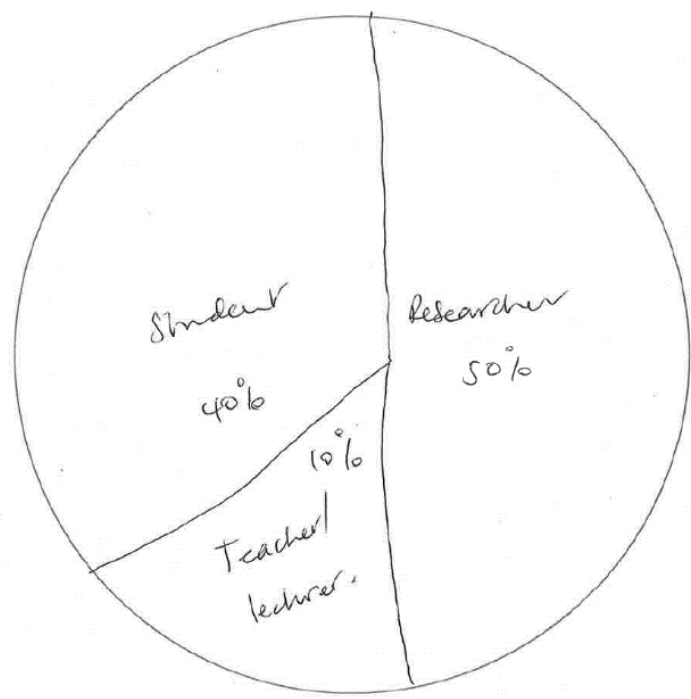

Figure 2: A20 
As noted before, those in the largest cluster place greatest significance on the researcher role. The exact emphasis on the researcher role, however, varies. A20 (Fig. 2, above) allocates 50 per cent of their academic identity to being a researcher, 40 per cent to being a student, and 10 per cent to being a teacher/lecturer. It suggests that the PGR is alert to the competing identities and whilst feeling somewhat in control over the thesis and the direction of the work, s/he still recognises the significance and status of the supervisor role.

Throughout the PGR TLA, participants were asked to comment on the assessment, feedback and teaching experiences they had as students. During these discussions, most of the PGRs would comment on their experiences on their degrees. The shift to being labelled a PGR was thus also a shift to being 'something more than' a student. The latter is common amongst PGRs as they walk the line between being viewed and treated as both students and colleagues alternately or even simultaneously, particularly if they are involved with teaching duties. Since none of the respondents, even at such an early stage of their PhDs, identified solely as a student it suggests that the identity shift is occurring at varying rates and to varying extents. As stated, it is likely that the PGR label and the frequency of its use in marketing and programme materials will affect the percentage given to the role of 'researcher'. If PGRs see the prestige of studying for a PhD as a key driver and motivation behind their studies then they may allocate more emphasis to this role.

The connection between status and prestige of the various identities forms part of the data accrued from the focus groups. In a pre-course survey, registered participants on the PGR TLA course were asked about the main reason they had decided to pursue a PhD with a few of them (9 out of 31) noting that it was the title that had encouraged them to engage with further study. When completers of the course were asked the same question, 6 out of 29 stated that they had been motivated by the esteem which they believed a doctorate would bring them. The desire to obtain the title of 'Doctor' may explain why some of the PGRs favoured the label of 'researcher' over 'student' at their current stage of their degree, as 'researcher' is a label that is associated with being an academic.
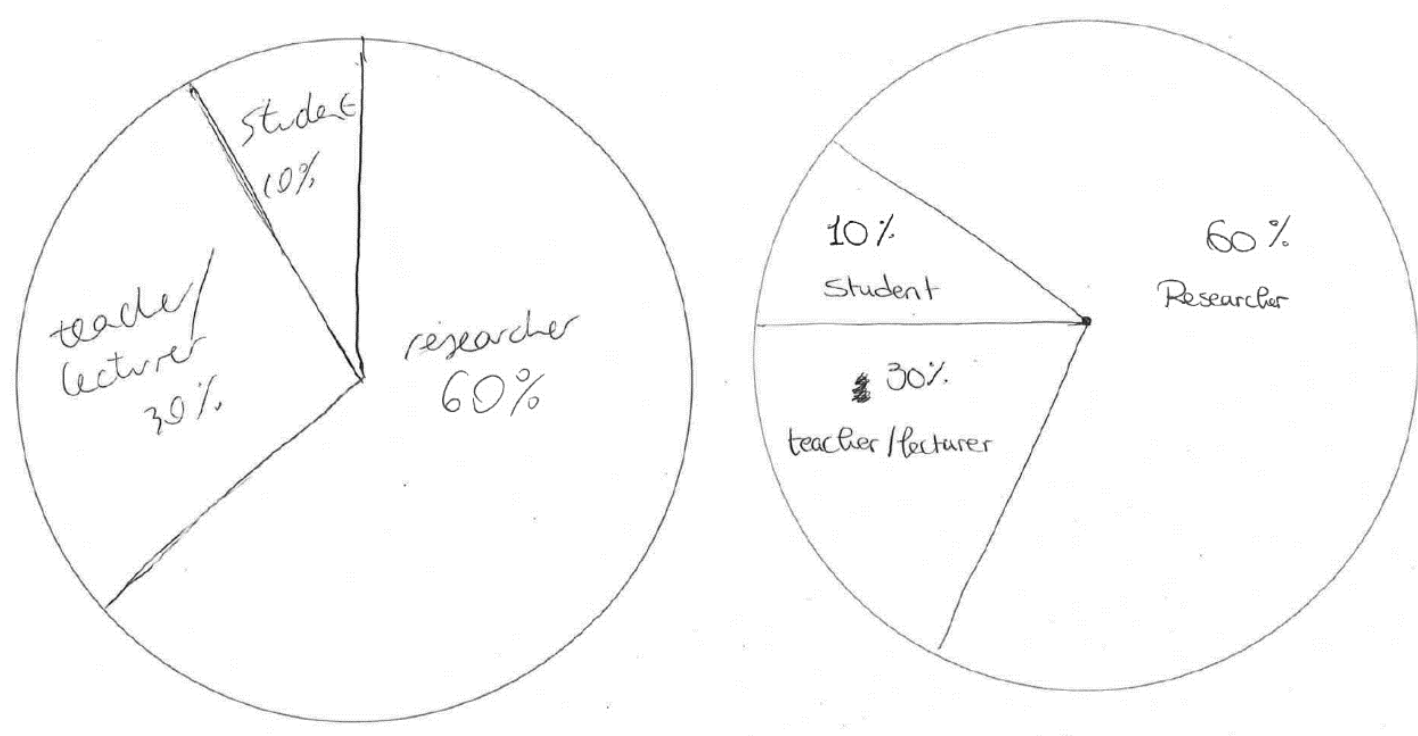

Figure 3: $A 7$ and $S 7$ 
A7 and S7 (Fig. 3, above) have the same breakdown of percentages with 30 per cent allocated to being the role of teacher/lecturer, 10 per cent on being a student, and 60 per cent to being a researcher. The relatively high 'teacher/ lecturer' proportion is interesting here. Is it aspirational? Many of the PGR respondents reported working directly with undergraduate students in a supportive or guiding capacity. We discovered that (particularly where lab work is a core feature in the research) direct contact and interaction with undergraduates from a 'superior' position was inevitable and sometimes preceded enrolment on the PGR TLA course.

As shown, the largest proportion of pie charts show a higher level of percentage allocated to the role of researcher. For example, S13 (Fig. 4, below) allocates a very specific 79 per cent to that of researcher, 20.5 per cent to being a student, and 0.5 per cent to viewing themselves as a teacher, suggesting either whimsy, or more likely, an acknowledgement of what they anticipate will come when the mandatory element is complete.

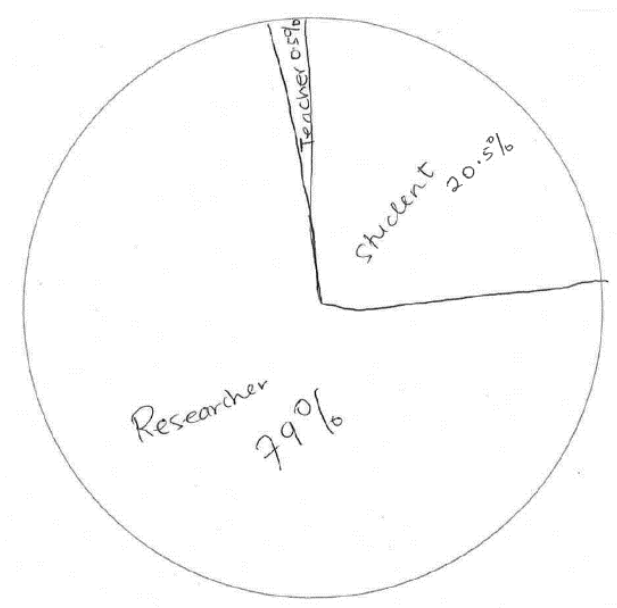

Figure 4: S13

The highest percentage allocated to being a researcher can be seen in pie charts A12 (Fig. 1, above) and S3 (Fig. 5, below), which both allocate 90 per cent to the role of researcher and 10 per cent to being a student.

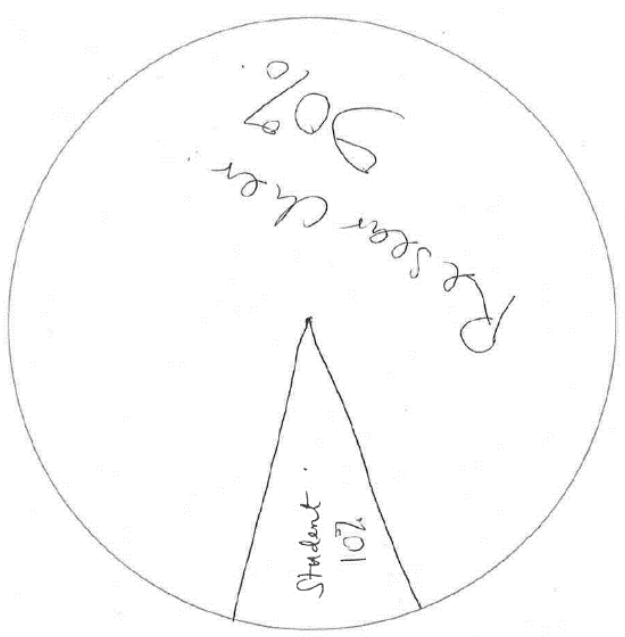

Figure 5: S3 
Do these pie charts reflect the level of control which these PGRs feel they have over their development and research? Or is this categorisation of identity a reflection of how they approach their work in general as PGRs? In an ideal world, the baseline expectation would be that undergraduate students study by reviewing their notes and digesting information from lectures and readings, critically regurgitating relevant information in exams and coursework. The way in which PGRs are expected to study is dramatically different. Their weeks are not taken up with timetabled classes and study is largely independent. The production of drafts for supervisors as regular check points throughout the years to track progress means the development of the thesis is crucial. The latter ultimately means different approaches to learning are employed in comparison to undergraduates. Study is more research focused, thus reinforcing the institutional term and self-concept formation as 'researchers' rather than 'students'. That there persists the connection to 'student' may not be an issue but it is noteworthy. Useful in this context is the conclusion from Baker and Lattuca (2010):

Learning and identity development go hand in hand - it is through participation in the intellectual community in the field and the home institution that doctoral students build the knowledge and skills required for scholarship in their field of study, and make choices about the roles and values associated with a career in the academy. In this sense, students' judgments of their knowledge and skills become self-assessments as a scholarly identity emerges during the $\mathrm{PhD}$ experience (p. 809).

Whilst we have found tendencies and categories, the diversity in the pie charts is, in itself, reason to pause and reflect. Again, we are not intimating that this is necessarily problematic but acknowledgement of this by those who work closely with PGRs may help how we interact with them. A3 and S14 (Fig. 6, below) are selected by way of representing those pie charts which are categorised into three sections.
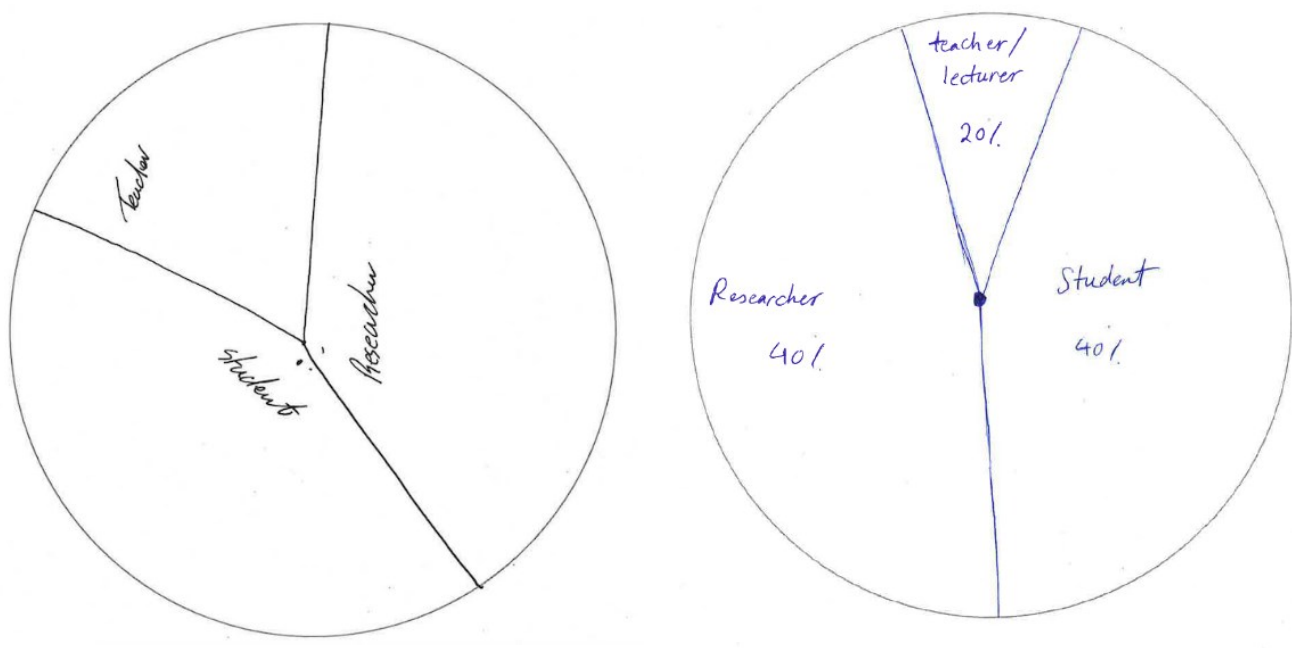

Figure 6: $\mathrm{A} 3$ and $\mathrm{S} 14$

11 pie charts were divided in this way, though the category of teacher/lecturer remained the smallest percentage - easily explained by the limited number of hours PGRs are allowed to 
be employed for teaching duties. It can be assumed that the pie charts which allocate a significant section to the role of the teacher/lecturer are drawn by PGRs who hold part time teaching support duties such as seminar leaders and/or lab demonstrators. However, there is another aspect regarding the context of courses which PGRs are expected to undertake as part of their degree which may help to explain the divisions in the pie charts. The PGR TLA is strand 2 of 5 that PGRs need to complete as part of their development programme. These strands may be in addition to any department-specific courses which PGRs may also be required to complete. The number of compulsory courses which PGRs need to engage with may therefore be impacting upon how they are perceiving themselves. If PGRs are spending a significant proportion of their time in compulsory classes, this would understandably make them feel as though they are still positioned within a 'student' role. The wider issue of whether the mandatory nature and content of all these course is suitable and relevant to all needs further consideration, not only in the context of their potential to stifle autonomy and the development of researcher identity.

In contrast to the pie charts and discussion points made above, A6 (Fig. 7, below) allocates a higher percentage to the role of being a student, with 10 per cent assigned to the role of teacher and 10 per cent to the role of lecturer. This particular pie chart does not assign any percentage to the role of being a researcher.

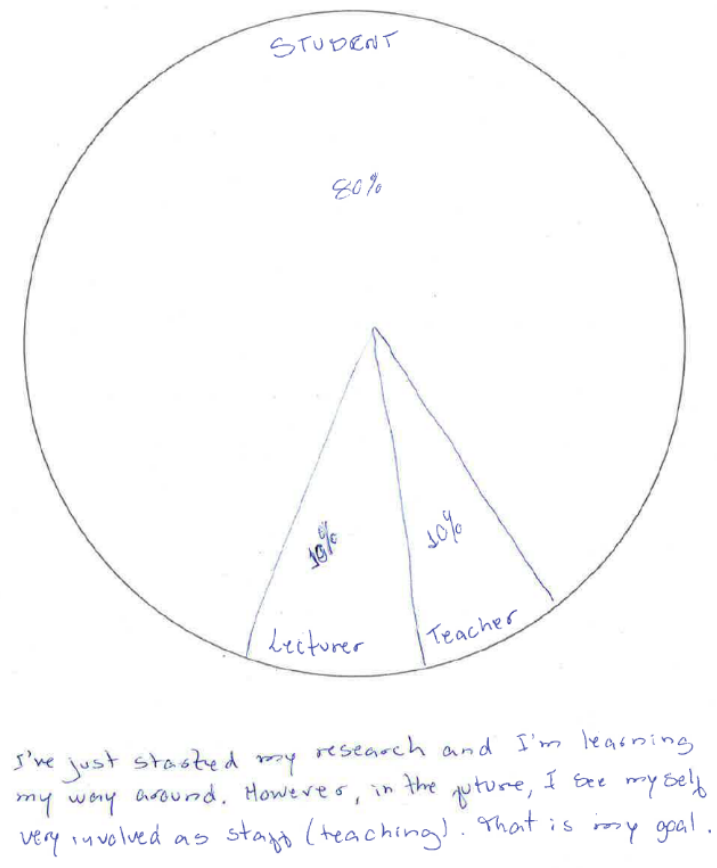

Figure 7: A6

The PGR explains this however in a note below the drawing by stating that 'I've just started my research and I'm learning my way around. However, in the future, I see myself very involved as staff (teaching). That is my goal'. What this pie chart mirrors is the argument made earlier that the perception of identity as being more of a student or researcher is dependent on the style of study being undertaken by the student. As this PGR has yet to begin fully researching her thesis area, she still feels as though she is a student, being led and directed by her supervisors. However, while she locates her current perception of identity in the pie chart by allocating 80 per cent to being a student, she also uses the pie 
chart to express her future goals of being viewed as a teacher and, separately, as a lecturer though at this stage, the distinction is unclear. For this particular student, the task of sketching out the way in which she perceives her academic identity, therefore, can only be answered by encapsulating both where she is situated now as well as how she sees her identity being formed in the future; pointing to the notion that identity is indeed fluid, moulded by circumstance and in constant flux.

A2 (Fig. 8, below) reveals an equal 50/50 split between the roles of researcher and student. The pie charts which are divided in this way raise the question of what it is that the PGRs view as being the key differences between being a researcher and a student. It is in many ways the perfect representation of the liminal space.

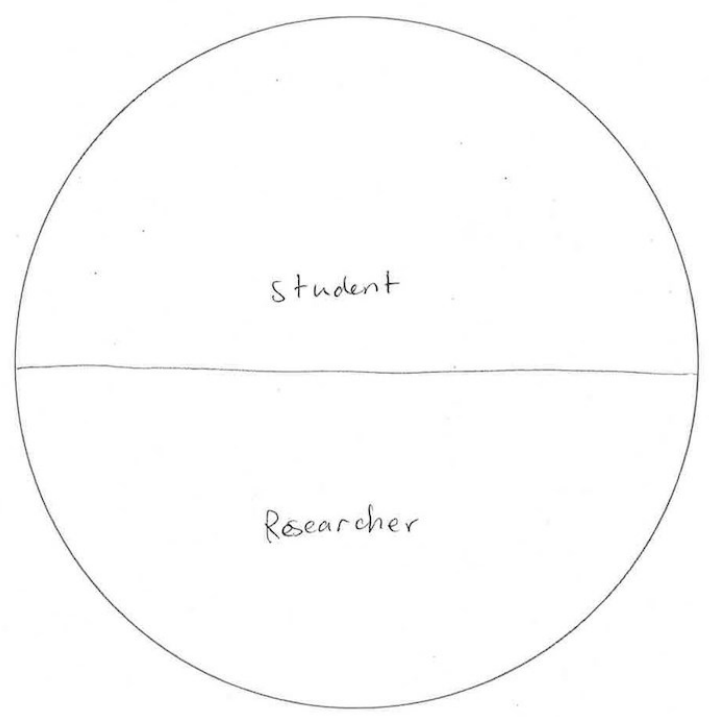

Figure 8: $A 2$

When placing the two side by side, those broad connotations of 'Researcher' as a more active participant, in control of her/ his studies and the direction of her/ his work alongside 'Student' as a more passive learner directed by an expert are more stark. Of course the wider structure of the PGR programme may have an effect. All PGRs have five mandatory strands at the start of their PhD related to research. In this context, it is likely that the sense of being a student will more likely form part of the PGR identity. Nevertheless, it is a simple but quite profound representation of someone in a transitional space. It serves as a reminder that just because we, as an institution, call someone a researcher, does not entirely define how they see themselves. Awareness of the multiple, changing and diverse ways of seeing and presenting themselves could and perhaps should do more to inform the ways in which we interact and work with them.

\section{Conclusion}

Whether referring to themselves as 'students', 'researchers' or 'teachers/lecturers', the way in which PGRs self-label may in itself influence how they behave and interact. The choice of label which PGRs choose from are understandably connected to the roles they play within the University, such as the limitations to how much and what type of teaching they can do. However, the terms themselves can also be interpreted to be revealing of the ways in which 
they view their position in relation to their studies and their supervisors. Furthermore, the labels which the PGRs assign themselves may point to how active or passive they feel in connection to their research degree as a whole.

The intention of this case study is not to make any grand claims. Rather, through an analysis of findings stemming from a very simple pie chart focused activity, we have tried to highlight the connections which can be made between PGR self-labelling and issues concerning identity and belonging. Though an unsophisticated activity from such simplicity can, at times, come clarity. The variance in the pie charts may have implications for the PGR system within the University and definitely tallies with the ad hoc discussions we both have previously had with many of the PGRs on the TLA course. These pie charts can be used to gain an insight into how PGRs view their identity within the University, and in this way point to the extent to which they feel connected with the institution.

Transitions by definition require movement from one place to another. How we see ourselves when negotiating the transition to and within $\mathrm{PhD}$ research may determine whether we experience a more positive liminality or the uncertainty of limbo. There will always be diversity in self-concept but beginning to understand the shape of this diversity may help stimulate reflection on how we treat and interact with PGRs and in doing so inform changes in practice that may support a more positive experience. The activity and our consideration of these snapshots has certainly helped shape the direction of our ongoing research and has encouraged us to use more deliberate and sophisticated iterations in future.

\section{Reference list}

Baker, V. and Lattuca, L. (2010). 'Developmental networks and learning: toward an interdisciplinary perspective on identity development during doctoral study'. Studies in Higher Education, 35(7), 807-827.

Colbeck, C. L. (2008). 'Professional identity development theory and doctoral education'. New Directions for Teaching and Learning, (113), 9-16.

Cotterall, S. (2015). 'The rich get richer: international doctoral candidates and scholarly identity'. Innovations in Education and Teaching International, 52(4), 360-370.

Crossouard, B. and Pryor, J. (2008). 'Becoming researchers: a sociocultural perspective on assessment, learning and the construction of identity in a professional doctorate'. Pedagogy, Culture \& Society, 16(3), 221-237.

Else, H. (2017) 'PhD students: time to make them university employees?', Times Higher, 18 May 2017, Available at: https://www.timeshighereducation.com/news/phd-students-time-tomake-them-university-employees [accessed: 26 May 2017].

Emmioğlu, E., McAlpine, L., \& Amundsen, C. (2017). 'Doctoral students' experıences of feelıng (or not) lıke an academıc'. International Journal of Doctoral Studies, 12, 73-90. 
Gauntlett, D., \& Holzwarth, P. (2006). 'Creative and visual methods for exploring identities'. Visual Studies, 21(01), 82-91.

Green, B. (2007). 'Unfinished business: Subjectivity and supervision'. Higher Education Research \& Development, 24(2), 151-163.

Guillemin, M., \& Drew, S. (2010). 'Questions of process in participant-generated visual methodologies'. Visual studies, 25(2), 175-188.

Harris, S. (2005). 'Rethinking academic identities in neo-liberal times'. Teaching in higher education, 10(4), 421-433.

Higher Education Academy (2011), The UK Professional Standards Framework for teaching and supporting learning in higher education. [Online]. Available at: https://www.heacademy.ac.uk/system/files/downloads/uk professional standards framewor k.pdf [Accessed: 26 May 2017].

Hoffman, M., Richmond, J., Morrow, J. and Salomone, K. (2016). 'Investigating "Sense of Belonging" in First-Year College Students'. Journal of College Student Retention: Research, Theory \& Practice, 4(3), 227-256.

Jazvac-Martek, M. (2009). 'Oscillating role identities: The academic experiences of education doctoral students'. Innovations in Education and Teaching International, 46(3), 253-264.

McAlpine, L. and Akerlind, G. (2010). Becoming an academic. Hampshire: Palgrave Macmillan.

McCormack, C. (2004). 'Tensions between student and institutional conceptions of postgraduate research'. Studies in Higher Education, 29(3), 319-334.

QAA (2010). Masters degree characteristics. [Online]. Available at:

http://www.qaa.ac.uk/academicinfrastructure/benchmark/masters/MastersDegreeCharacteris tics.pdf [Accessed: 18 May 2017]

Times Higher Education (anonymous contributors) (2017) 'Of monsters and mentors: PhD disasters, and how to avoid them' Times Higher, 1 June, Available at:

https://www.timeshighereducation.com/features/monsters-and-mentors-phd-disasters-andhow-to-avoid-them [Accessed: 3 June 2017]

Vitae (2010). Researcher Development Framework. [Online].

https://www.vitae.ac.uk/researchers-professional-development/about-the-vitae-researcherdevelopment-framework/vitae-researcher-development-framework-rdf-domains-graphic2011.jpg [Accessed: 26 May 2017].

Vitae (2017). About us: Realising the potential of researchers, globally. [Online]. Available: https://www.vitae.ac.uk/about-us [Accessed: 3 June 2017].

Yeatman, A. (1995). 'Making supervision relationships accountable: graduate student logs'. Australian Universities' Review, 38(2), 9-11. 